\title{
PPAR $\alpha$ agonists regulate lipid metabolism and nitric oxide production and prevent placental overgrowth in term placentas from diabetic rats
}

\author{
Nora Martínez, Melisa Kurtz, Evangelina Capobianco, Romina Higa, Verónica White \\ and Alicia Jawerbaum
}

Laboratory of Reproduction and Metabolism, CEFYBO-CONICET, School of Medicine, University of Buenos Aires, Paraguay 2155, 17th floor, 1121ABG Buenos Aires, Argentina

(Correspondence should be addressed to A Jawerbaum; Email: a.jawerbaum @gmail.com)

\begin{abstract}
Maternal diabetes impairs fetoplacental metabolism and growth. Peroxisome proliferator-activated receptor $\alpha($ PPAR $\alpha)$ is a nuclear receptor capable of regulating lipid metabolism and inflammatory pathways. In this study, we analyzed whether placental and fetal PPAR $\alpha$ activation regulates lipid metabolism and nitric oxide (NO) production in term placentas from diabetic rats. Diabetes was induced by neonatal streptozotocin administration. On day 21 of pregnancy, placentas from control and diabetic rats were cultured in the presence of PPAR $\alpha$ agonists (clofibrate and leukotriene $B_{4}\left(L_{T B}\right)$ ) for further evaluation of levels, synthesis, and peroxidation of lipids as well as NO production. Besides, on days 19, 20, and 21 of gestation, fetuses were injected with $\mathrm{LTB}_{4}$, and the placentas were explanted on day 21 of gestation for evaluation of placental weight and concentrations of placental lipids, lipoperoxides, and NO metabolites. We found that placentas from diabetic rats showed reduced PPAR $\alpha$ concentrations. They presented no lipid overaccumulation but reduced lipid synthesis, parameters negatively regulated by PPAR $\alpha$ activators. Lipid peroxidation and NO production, increased in placentas from diabetic rats, were negatively regulated by PPAR $\alpha$ activators. Fetal PPAR $\alpha$ activation in diabetic rats does not change placental lipid concentrations but reduced placental weight and NO production. In conclusion, PPAR $\alpha$ activators regulate lipid metabolism and NO production in term placentas from diabetic rats, an activation that regulates placental growth and can partly be exerted by the developing fetus.
\end{abstract}

Journal of Molecular Endocrinology (2011) 47, 1-12

\section{Introduction}

Maternal diabetes impairs fetal and placental development, metabolism, and growth. Both type 1 and type 2 diabetes increase the risks of miscarriage and malformations (Balsells et al. 2009, Michael Weindling 2009). Gestational, type 1 , and type 2 diabetes increase the risks of perinatal morbidity and mortality and also program increases in the risks of metabolic and cardiovascular diseases in the offspring's life (Plagemann et al. 2008, Melamed \& Hod 2009, Reece et al. 2009).

A hallmark related to the programming of metabolic diseases is the overgrowth observed in both the fetuses and their placentas at term gestation (Jansson et al. 2006, Plagemann et al. 2008). Fetal overgrowth is mainly the result of an increase in metabolic substrates transferred through the placenta and of the increase of insulin produced in fetal pancreas as a response to the increased glucose concentrations (Desoye \& Shafrir 1994, Jansson et al. 2006, Herrera \& Ortega-Senovilla 2010). Indeed, together with the increased insulin-like growth factors, these changes may guide the metabolic and proliferative changes that lead to both fetal and placental overgrowth (Hiden et al. 2009). In addition, in the placenta, nitric oxide (NO) can dilate placental vessels and induce angiogenesis and trophoblast proliferation (Dulak \& Jozkowicz 2003, Valdes et al. 2009), and NO overproduction is observed in intrauterine tissues in human diabetic gestations and in experimental diabetic models (Jawerbaum \& Gonzalez 2005, San Martin \& Sobrevia 2006, Leach et al. 2009).

There are several experimental models of diabetes that show similar impairments in fetoplacental development and growth when compared to human diabetic pregnancies (Jawerbaum \& White 2010). These models have been valuable to address the causes of these impairments, which are related, at least in part, to the intrauterine metabolic impairments and the consequent generation of an excess of reactive oxygen and nitrogen species, which leads to a pro-inflammatory environment that exerts damage throughout development (Myatt \& Cui 2004, Jawerbaum \& Gonzalez 2006).

As mechanisms capable of stimulating metabolic and anti-inflammatory pathways could be beneficial to placental development in maternal diabetes, we here 
focus on the activity of the nuclear receptor peroxisome proliferator-activated receptor $\alpha($ PPAR $\alpha)$. This nuclear receptor is one of the three PPAR isotypes, ligandactivated transcription factors that regulate metabolic and inflammatory pathways (Bensinger \& Tontonoz 2008). Through its classical pathway, PPAR $\alpha$ heterodimerizes with its partner RXR and after ligand binding, they recruit coactivators and release corepressors leading to the expression of target genes (Hihi et al. 2002). The huge ligand pocket characteristic of PPARs accepts different ligands, such as different polyunsaturated fatty acids, which can activate the three PPAR isotypes, and the arachidonic acid derivative leukotriene $\mathrm{B}_{4}\left(\mathrm{LTB}_{4}\right)$, which is a specific ligand of the PPAR $\alpha$ isotype (Lin et al. 1999, Hihi et al. 2002, Narala et al. 2010). Besides, clofibrate is a pharmacological PPAR $\alpha$ activator frequently used to treat dyslipidemias (Desvergne et al. 2004, Panadero et al. 2009).

PPAR $\alpha$ is highly expressed in several organs such as the liver and the heart, in which PPAR $\alpha$ ligands are crucial regulators of lipid catabolism (Lefebvre et al. 2006, Finck 2007, Rakhshandehroo et al. 2007). Besides, $\operatorname{PPAR} \alpha$ activation prevents lipid peroxidation and regulates anti-inflammatory pathways in several tissues (Cuzzocrea et al. 2008, Belfort et al. 2010). In addition, when PPAR $\alpha$ is activated, NO generation is inhibited in various tissues and cell types, in part by reducing the concentrations of the inducible form of NO synthase (iNOS; Paukkeri et al. 2007, Cuzzocrea et al. 2008, Ibarra-Lara et al. 2010).

PPAR $\alpha$ is expressed in the placenta and in different fetal organs during the post-placentation stage (Braissant \& Wahli 1998, Wang et al. 2002). Our previous studies have shown that $\operatorname{PPAR} \alpha$ activation regulates lipid catabolism and synthesis in placentas from diabetic rats in an early post-placentation period (day 14 of rat gestation; Martinez et al. 2008). Besides, we have recently shown that lipid accumulation and peroxidation in fetal livers from diabetic rats at term gestation can be regulated by PPAR $\alpha$ activators (Martinez et al. 2011). Interestingly, we have also found that fetal activation with the endogenous ligand $\mathrm{LTB}_{4}$ can prevent fetal and fetal liver overgrowth in maternal diabetes (Martinez et al. 2011). Owing to the relevance in understanding the relationship between fetal growth and placental growth, we consider these findings as a starting point to address fetal effects on placental growth. Therefore, we here investigated the effects of the pharmacological $\operatorname{PPAR} \alpha$ activator clofibrate and the endogenous PPAR $\alpha$ activator $\mathrm{LTB}_{4}$ on placental lipid concentrations, synthesis, and peroxidation, as well as on placental NO production in term pregnant control and diabetic rats (day 21 of pregnancy). Besides, in both control and diabetic animals, we injected fetuses with the endogenous PPAR $\alpha$ activator $\mathrm{LTB}_{4}$ on days 19, 20, and 21 of pregnancy and analyzed their corresponding placentas on day 21 of gestation to address the placental lipid concentrations, lipoperoxidation, and NO production, as well as PPAR $\alpha$ expression and the placental weight.

\section{Materials and methods}

\section{Animals}

Albino Wistar rats bred in our laboratory were fed ad libitum with commercial rat chow (Asociación cooperativa Argentina, Buenos Aires, Argentina). At 2 days of age, neonates were injected with streptozotocin (90 mg/kg, s.c., Sigma-Aldrich) diluted in citrate buffer $(0.05 \mathrm{M}, \mathrm{pH} 4.5$, Sigma-Aldrich) as described previously (Portha et al. 1979, Capobianco et al. 2008). Control animals were injected with citrate buffer alone. The diabetic state was confirmed in 2-month-old rats prior to mating. Rats were considered diabetic when they presented fasting glycemic values higher than $130 \mathrm{mg} / \mathrm{dl}$. Glycemia was determined in blood from the tail central vein by Accu-Chek reagent strips and a glucometer obtained from Accu-Chek, Roche Diagnostics. Control and diabetic female rats were mated with control males. Pregnancy was confirmed by the presence of spermatozoa in vaginal smears and this day was considered day 1 of gestation. The guidelines for the care and use of animals approved by the local institution were followed, according to the Principles of Laboratory Animal Care (NIH publication number 85-23, revised 1985, http://grants1.nih.gov/grants/ olaw/references/phspol.htm).

\section{Placental preparations}

Animals were killed in a $\mathrm{CO}_{2}$ chamber on day 21 of pregnancy and the uterus of each animal was transferred to a Petri dish containing Krebs Ringer bicarbonate (KRB) medium: $5 \mathrm{mM}$ glucose, $145 \mathrm{mM}$ $\mathrm{Na}^{+}, 2.2 \mathrm{mM} \mathrm{Ca}{ }^{2+}, 1.2 \mathrm{mM} \mathrm{Mg}^{2+}, 127 \mathrm{mM} \mathrm{Cl}^{-}$, $25 \mathrm{mM} \mathrm{HCO}_{3}^{-}, 1.2 \mathrm{mM} \mathrm{SO} \mathrm{SO}_{4}^{-}$, and $1.2 \mathrm{mM} \mathrm{PO}_{4}^{3-}$. Fetuses and placentas were explanted and weighed. Placentas $(100 \mathrm{mg})$ were frozen at $-80{ }^{\circ} \mathrm{C}$ for evaluation of protein expression of PPAR $\alpha$. In order to analyze the effect of $\operatorname{PPAR} \alpha$ on lipid concentrations, de novo lipid synthesis, lipid peroxidation, and NO production, placental explants $(100 \mathrm{mg})$ were incubated for $3 \mathrm{~h}$ as previously (Martinez et al. 2008) in a metabolic shaker under an atmosphere of $5 \% \mathrm{CO}_{2}$ in air at $37^{\circ} \mathrm{C}$, with or without the addition of either $\mathrm{LTB}_{4}$ $(0 \cdot 1 \mu \mathrm{M}$, Cayman Chemical Co., Ann Arbor, MI, USA) or clofibrate $(20 \mu \mathrm{M}$, Sigma-Aldrich). Thereafter, tissues were frozen at $-80^{\circ} \mathrm{C}$ for further analysis of lipid concentrations, lipid peroxidation, and NO production. To analyze the de novo lipid synthesis, 
placentas $(100 \mathrm{mg})$ were incubated as described above, with addition of $1 \mu \mathrm{Ci}{ }^{14} \mathrm{C}$-acetate $(53 \mathrm{mCi} / \mathrm{mmol})$ and then stored at $-80{ }^{\circ} \mathrm{C}$ until determination of the newly formed radioactive lipids, as described below. Maternal glycemia and triglyceridemia were measured by commercial enzymatic kits from Wiener Lab (Rosario, Argentina) in serum obtained through centrifugation of blood from the aorta artery.

To perform the in vivo studies, we proceeded as described previously (Martinez et al. 2011). Fetuses from pregnant animals received either a $50 \mu \mathrm{l}$ s.c. injection of $\mathrm{LTB}_{4}(340 \mathrm{mg} / \mathrm{kg}$ dissolved in vehicle) or vehicle alone ( $17 \mu \mathrm{mol}$ ethanol $/ \mathrm{kg}$, dissolved in saline solution) on days 19, 20, and 21 of pregnancy. For this purpose, the pregnant animals were anesthetized in a $\mathrm{CO}_{2}$ chamber and a slight anesthesia maintained with ether vapors. An abdominal incision allowed the exposure of the wall of the left uterine horn, through which the fetuses were injected. The entire surgery lasted $15 \mathrm{~min}$ and was repeated for three consecutive days. In each animal, fetuses in the left uterine horn were numbered according to their distance to the ovary. Of the fetuses, two were injected with $\mathrm{LTB}_{4}$ solution for the three consecutive days, whereas two other fetuses were injected with vehicle for the three consecutive days. After the injection, the abdominal incision was sutured. Fetuses from eight control and eight diabetic animals were subjected to this surgery procedure. After $3 \mathrm{~h}$ of the last injection (day 21 of pregnancy), animals were killed in a $\mathrm{CO}_{2}$ chamber. The uterus of each animal was transferred to a Petri dish containing KRB medium. Fetuses and placentas were explanted and weighed. Placentas $(100 \mathrm{mg})$ were stored at $-80^{\circ} \mathrm{C}$ for further analysis of lipid concentrations, lipid peroxidation, and $\mathrm{NO}$ production or preserved in RNA-later stabilization solution (Ambion) for the evaluation of the gene expression of iNOS and PPAR $\alpha$. Fetal blood was obtained from decapitation, collected in heparinized syringes, and the plasma preserved at $-80^{\circ} \mathrm{C}$ for further evaluation of triglyceridemia and glycemia levels by using commercial kits obtained from Wiener Lab.

\section{PPAR $\alpha$ concentrations}

PPAR $\alpha$ protein expression was evaluated by western blot as described previously (Martinez et al. 2008). Placentas were homogenized in $300 \mu \mathrm{l}$ ice-cold lysis buffer ( $\mathrm{pH}$ $7 \cdot 4,20 \mathrm{mM}$ Tris- $\mathrm{HCl}, 150 \mathrm{mM} \mathrm{NaCl}$, and $1 \%$ Triton $\mathrm{X}-100)$ containing $1 \%$ protease inhibitor cocktail (Sigma-Aldrich), incubated on ice for $2 \mathrm{~h}$, and centrifuged at $9600 \mathrm{~g}$ for $10 \mathrm{~min}$ at $4{ }^{\circ} \mathrm{C}$. Protein concentrations were determined by the Bradford method. An equivalent volume of $100 \mu \mathrm{g}$ of protein lysates was separated by electrophoresis in $12 \%$ SDS-PAGE. Proteins were then transferred onto nitrocellulose membranes, which were blocked with $2 \%$ BSA for $24 \mathrm{~h}$ and then incubated overnight at $4{ }^{\circ} \mathrm{C}$ with a polyclonal rabbit IgG antibody either against PPAR $\alpha$ (1:200; Cayman Chemical Co.) or against $\alpha$-actin (Sigma-Aldrich). After washing with Tris buffer saline and Tween $0.05 \%$, the blots were treated with HRPconjugated secondary antibody (1:10000) obtained from Jackson ImmunoResearch Laboratories, Inc. (West Grove, PA, USA) for $1 \mathrm{~h}$ and washed several times. The specific signals were visualized using the ECL Western Blotting Analysis System from G. E. Healthcare (Buckinghamshire, UK) enhanced chemiluminescence system. This kit uses Lumigen TMA-6, which is a substrate for the chemiluminescent detection of peroxidase conjugates on membranes. Reaction of the substrate with a HRP label generates sustained luminescence of high intensity. The identity of PPAR $\alpha$ was established by the use of molecular weight standards (Invitrogen), which allow the identification of the band revealed at the expected size of $50 \mathrm{kDa}$, which was absent in the negative control experiments performed in the absence of primary antibody and present in the liver homogenates used as a positive control. Actin reactivity was detected with a phosphatase alkaline-conjugated secondary antibody (Santa Cruz Biotechnology, Santa Cruz, CA, USA). The relative intensity of protein signals was quantified by densitometric analysis using the Image J Software (NIH, Bethesda, MD, USA). Results are expressed as PPAR $\alpha$ protein/actin protein ratio.

\section{Lipid level analysis}

Placental lipid concentrations were evaluated by thin layer chromatography (TLC) as described previously (Capobianco et al. 2008). Placentas were homogenized in PBS. Liver lipids were extracted by three rounds of organic extraction in methanol:chloroform (2:1) and the solvent evaporated under a $\mathrm{N}_{2}$ stream. Lipids were developed by TLC in thin silica gel 60 plates (Merck) using hexane:ether:acetic acid (80:20:2) as the developing solvent mixture. Lipid species were stained with iodine. Triglycerides, cholesterol, cholesteryl esters, and phospholipids were identified and quantified by comparison with known amounts of pure lipid standards obtained from Nu-Chek-Prep (Elysian, MN, USA), on the same plate. The plates were scanned and analyzed by densitometry using the ImageJ software. Results are expressed as $\mu \mathrm{g} / \mathrm{mg}$ protein.

\section{Evaluation of the de novo lipid synthesis}

Placental lipid synthesis from ${ }^{14} \mathrm{C}$-acetate was evaluated as described previously (Capobianco et al. 2008). Briefly following the incubations performed in the presence of 
${ }^{14} \mathrm{C}$-acetate $(53 \mathrm{mCi} / \mathrm{mmol})$ either with or without the addition of $\mathrm{LTB}_{4}(0 \cdot 1 \mu \mathrm{M})$ or clofibrate $(20 \mu \mathrm{M})$, lipids were separated by TLC as described above. The radioactive spots were identified with a STORM scanner (G. E. Healthcare). Thereafter, the radioactive spots corresponding to the different ${ }^{14} \mathrm{C}$-labeled lipid species were scrapped into vials and counted in a liquid scintillation counter. Results are expressed as $\mathrm{dpm} / \mu \mathrm{g}$ protein.

\section{Lipid peroxidation evaluation}

Lipid peroxidation was estimated by measuring the concentrations of thiobarbituric acid reactive substances (TBARS), as described previously (Kurtz et al. 2010), a method widely used to assess peroxidation of fatty acids (Ohkawa et al. 1979). Approximately $100 \mathrm{mg}$ of tissue was homogenized in $100 \mathrm{mM}$ Tris-HCl buffer, pH 7•6. The homogenate was added to trichloroacetic acid $(40 \%)$ and centrifuged at $1.8 \mathrm{~g}$ for $10 \mathrm{~min}$. The supernatant was added with an equal volume of thiobarbituric acid $(46 \mathrm{mM})$, and the solution was heated at $95{ }^{\circ} \mathrm{C}$ for $15 \mathrm{~min}$. Then, the samples were cooled and quantified spectrophotometrically at $530 \mathrm{~nm}$. Malondialdehyde (Sigma-Aldrich) subjected to the same conditions as the tissue homogenates was used as a standard. TBARS are expressed as $\mathrm{nmol} / \mathrm{mg}$ protein.

\section{NO production analysis}

NO production was evaluated by the determination of the concentration of its stable metabolites nitrates/ nitrites, as described previously (Higa et al. 2010), by using a commercial assay kit (Cayman Chemical Co.). For that, placental tissues were homogenized in $1 \mathrm{ml}$ Tris-HCl buffer $\mathrm{pH} 7 \cdot 6$ and an aliquot was separated for protein determination. Nitrates in the supernatant were reduced to nitrites using nitrate reductase, and total nitrites were measured by the Griess method (Green et al. 1982). Optical densities were measured at $540 \mathrm{~nm}$ in a microliter plate using $\mathrm{NaNO}_{3}$ and $\mathrm{NaNO}_{2}$ as standard. Results are expressed as $\mathrm{nmol} / \mathrm{mg}$ of protein.

\section{Assessment of iNOS and PPAR $\alpha$ mRNA}

iNOS and PPAR $\alpha$ expression was evaluated by RT-PCR, as described previously (Kurtz et al. 2010). Placental RNA was extracted with Tri reagent (Genbiotech, Buenos Aires, Argentina) in accordance with the manufacturer's instructions. cDNA was synthesized incubating $1 \mu \mathrm{g}$ extracted placental RNA with $20 \mu \mathrm{l}$ reverse transcription buffer containing $7.5 \mathrm{mM}$ random primer hexamers (Promega), 0.5 mM each of all four dNTPs (Invitrogen) and $200 \mathrm{U}$ MMLV reverse transcriptase (Invitrogen) at $25^{\circ} \mathrm{C}$ for $10 \mathrm{~min}$, then at $37^{\circ} \mathrm{C}$ for $50 \mathrm{~min}$, and then at $70{ }^{\circ} \mathrm{C}$ for $15 \mathrm{~min}$. cDNA $(2 \mu \mathrm{l})$ was used to perform the amplification in a $25 \mu \mathrm{l}$ reaction buffer containing dNTPs $(0.2 \mathrm{mM})$, magnesium chloride solution $(2 \mathrm{mM}), 1.25 \mathrm{U}$ Taq polymerase (GoTaq Flexi Polymerase, Promega), and $0.45 \mu \mathrm{M}$ of each specific primer.

Primers for iNOS were forward: $5^{\prime}$-TGGTGAAGGGTGTCGTGAAA- $3^{\prime}$ and reverse: 5'-CTCACTGGGACTGCACAGAA-3', whose amplification product is a 128 bp fragment (Nowicki et al. 2003). Primers for PPAR $\alpha$ were forward: $5^{\prime}$-TCACACAATGCAATCCGTTT$3^{\prime}$ and reverse: 5'-GGCCTTGACCTTGTTCATGT-3', whose amplification product is a $177 \mathrm{bp}$ fragment (Yeon et al. 2004). The primers for the ribosomal protein L30, used as an internal control, were forward: 5'-CCATCTTGGCGTCTGATCTT- ${ }^{\prime}$ and reverse: $5^{\prime}$-GGCGAGGATAACCAATTTC-3 ${ }^{\prime}$, designed to obtain a 201 bp fragment, using Primer 3 Software (http:/ / frodo.wi. mit.edu/primer3). The initial step in the reaction was $95^{\circ} \mathrm{C}$ for $5 \mathrm{~min}$, followed by 28 cycles for L30, 34 cycles for iNOS, and 36 cycles for PPAR $\alpha$. Each cycle consisted of denaturation at $95^{\circ} \mathrm{C}$ for $15 \mathrm{~s}$, primer annealing at $58{ }^{\circ} \mathrm{C}$ for $30 \mathrm{~s}$, and extension at $72{ }^{\circ} \mathrm{C}$ for $15 \mathrm{~s}$. The resulting products $(10 \mu \mathrm{l})$ were separated on a $2 \%$ agarose gel and stained with ethidium bromide. The density of the bands was quantified by image analysis with Image J Software and normalized to L30.

\section{Statistical analysis}

Data are presented as the mean \pm s.E.M. Groups were compared using Student's $t$-test or one-way ANOVA in conjunction with Tukey's test where appropriate. Differences between groups were considered significant when $P$ value $<0 \cdot 05$.

\section{Results}

\section{PPAR $\alpha$ in term placentas from control and diabetic rats}

Diabetic animals at term gestation showed increased glycemia (control: $101 \pm 9$; diabetic: $282 \pm 31 \mathrm{mg} / \mathrm{dl}$, $P<0.001$ ) and triglyceridemia (control: $199 \pm 15$; diabetic: $554 \pm 61 \mathrm{mg} / \mathrm{dl}, P<0 \cdot 001)$. Together with these metabolic changes, there was an increase in placental weight in the diabetic group (control: $561 \pm 11 \mathrm{mg}$; diabetic: $670 \pm 18 \mathrm{mg}, P<0 \cdot 001)$. As a putative regulator of metabolic pathways in term placentas, we measured the protein expression of PPAR $\alpha$ in placentas from control and diabetic rats on day 21 of gestation. We found that PPAR $\alpha$ concentrations in placentas from diabetic animals were reduced $(P<0.05)$ when compared with those from healthy rats (Fig. 1). 

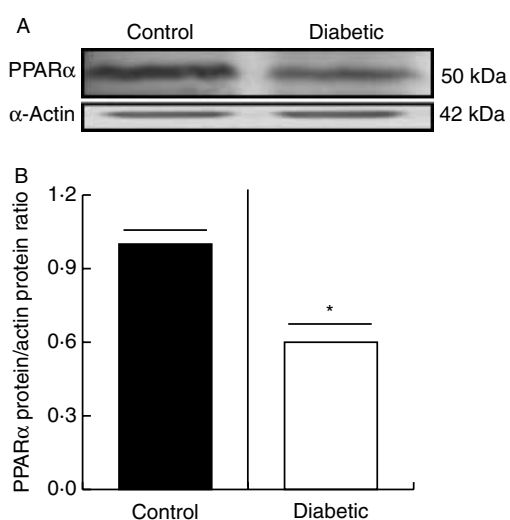

Figure 1 Protein expression of PPAR $\alpha$ is reduced in term placentas from diabetic rats. Antibodies used were rabbit antiPPAR $\alpha$ and rabbit anti-actin. (A) Representative western blots exhibiting PPAR $\alpha$ protein expression in placentas from control and diabetic rats. (B) Densitometric analysis of PPAR $\alpha$ concentrations, normalized against actin, used as an internal control. Values are mean \pm S.E.M. for placentas obtained from eight rats on day 21 of gestation. Student's $t$-test was performed. ${ }^{*} P<0.05$ denotes differences between diabetic versus control groups.

\section{Lipid concentrations and de novo synthesis in term placentas from control and diabetic rats: effect of PPAR $\alpha$ activation}

The placentas from diabetic rats on day 21 of gestation showed no changes in the concentrations of triglycerides, cholesteryl esters, phospholipids, and cholesterol when compared with controls (Fig. 2). To analyze the effects of PPAR $\alpha$ agonists on placental lipid concentrations, three placentas from control $(n=8)$ and three from diabetic $(n=8)$ rats were explanted on day 21 of gestation and cultured for $3 \mathrm{~h}$ in the presence or absence of the PPAR $\alpha$ agonists $\operatorname{LTB}_{4}(0 \cdot 1 \mu \mathrm{M})$ or clofibrate $(20 \mu \mathrm{M})$, and placental lipid concentrations were then evaluated. We found that $\mathrm{LTB}_{4}$ did not modify the concentrations of the evaluated lipids in placentas from both control and diabetic rats, while clofibrate reduced triglycerides $(P<0 \cdot 01)$ and cholesterol $(P<0.05)$ concentrations in control placentas, and reduced the concentrations of cholesteryl esters $(P<0.05)$ and phospholipids $(P<0 \cdot 05)$ in placentas from diabetic rats (Fig. 2).

When the de novo lipid synthesis was evaluated in the placentas on day 21 of gestation, we found that the de novo synthesis of triglycerides $(P<0.001)$ and phospholipids $(P<0 \cdot 01$; Fig. 3$)$ was reduced and that there were no changes in the de novo synthesis of cholesterol and cholesteryl esters in the placentas from diabetic animals when compared with controls. To analyze the effects of PPAR $\alpha$ agonists on placental de novo lipid synthesis, three placentas from control $(n=8)$ and three from diabetic $(n=8)$ rats were explanted on day 21 of gestation and cultured for $3 \mathrm{~h}$ in the presence of ${ }^{14} \mathrm{C}$-acetate as a tracer either with or without addition of $\mathrm{LTB}_{4}(0 \cdot 1 \mu \mathrm{M})$ or clofibrate $(20 \mu \mathrm{M})$, and concentrations of radioactive lipids in the placentas were then analyzed. We found that neither clofibrate nor $\mathrm{LTB}_{4}$ modified the de novo synthesis of the evaluated lipids in the placentas from control rats (Fig. 3). Differently, in the placentas from diabetic animals, the endogenous ligand $\mathrm{LTB}_{4}$ reduced the de novo synthesis of phospholipids $(P<0.001)$ and cholesterol $(P<0 \cdot 05)$, whereas the pharmacological ligand clofibrate reduced the de novo synthesis of triglycerides $(P<0.05)$, phospholipids $(P<0.05)$, and cholesterol $(P<0 \cdot 05$; Fig. 3$)$.

\section{Lipid peroxidation and NO production in placentas from control and diabetic rats at term gestation: effect of PPAR $\alpha$ activation}

The placentas from diabetic rats on day 21 of gestation showed increased lipid peroxidation, as indicated by an increase in the concentrations of TBARS $(P<0 \cdot 01$, Fig. 4A), as well as increased NO production, as indicated by an increase in its stable metabolites nitrates/nitrites $(P<0 \cdot 05$, Fig. 4B). To analyze the effects of PPAR $\alpha$ agonists on placental lipid peroxidation and NO production, three placentas from
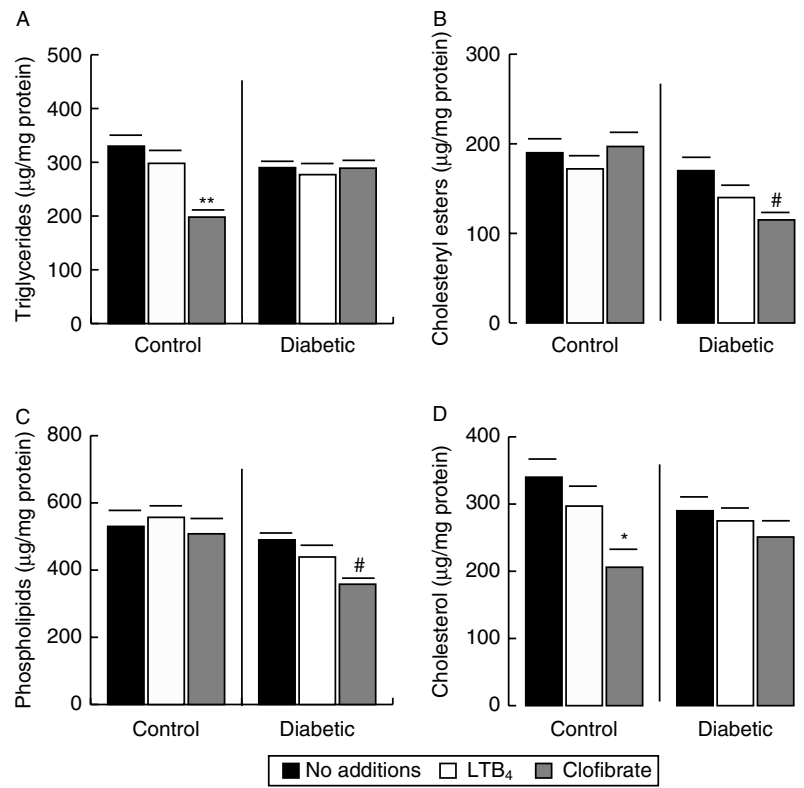

Figure 2 PPAR $\alpha$ activators regulate lipid concentrations in term placentas from diabetic rats. Effects of the PPAR $\alpha$ agonists $\operatorname{LTB}_{4}(0 \cdot 1 \mu \mathrm{M})$ and clofibrate $(20 \mu \mathrm{M})$ on lipid concentrations in placentas obtained from control and diabetic rats on day 21 of gestation. (A) Triglycerides, (B) cholesteryl esters, (C) phospholipids, and (D) cholesterol. Values are mean \pm S.E.M. for placentas obtained from eight rats on day 21 of gestation. ANOVA followed by Tukey's test was performed. ${ }^{*} P<0.05$ and ${ }^{* *} P<0.01$ denote differences between treated control group versus non-treated control group. ${ }^{\#} P<0.05$ denotes differences between treated diabetic group versus non-treated diabetic group. 

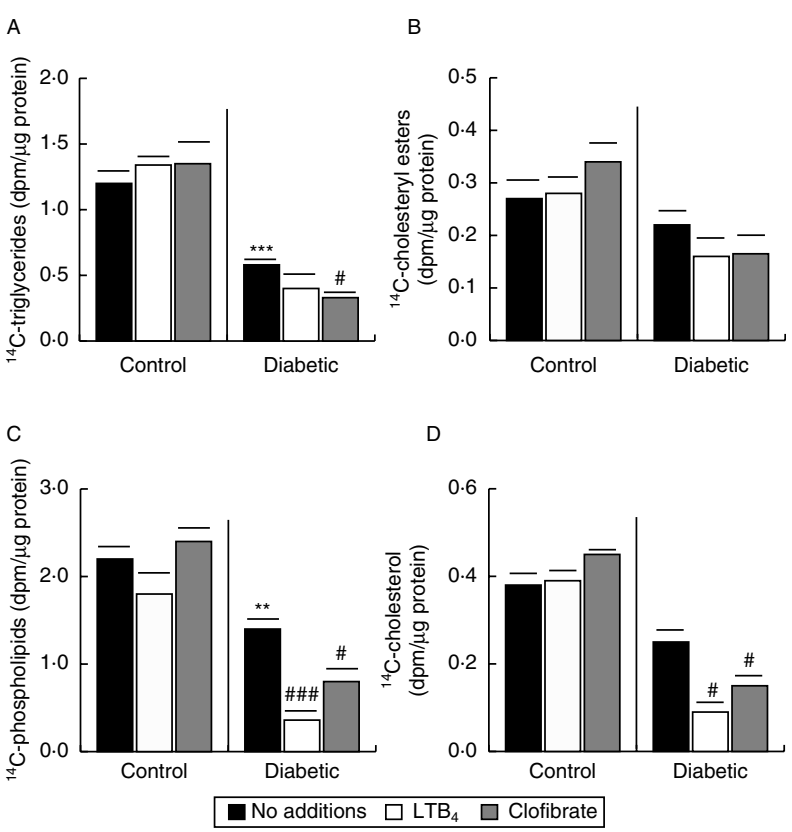

Figure 3 PPAR $\alpha$ activators regulate the de novo lipid synthesis in term placentas from diabetic rats. Effects of the PPAR $\alpha$ agonists $\operatorname{LTB}_{4}(0 \cdot 1 \mu \mathrm{M})$ and clofibrate $(20 \mu \mathrm{M})$ on the de novo lipid synthesis in term placentas obtained from control and diabetic rats.

(A) Triglycerides, (B) cholesteryl esters, (C) phospholipids, and (D) cholesterol. Values are mean \pm S.E.M. for placentas obtained from eight rats on day 21 of gestation. ANOVA followed by Tukey's test was performed. ${ }^{\star \star} P<0.01$ and ${ }^{\star \star *} P<0.001$ denote differences between non-treated diabetic group versus non-treated control group. ${ }^{\#} P<0.05$ and ${ }^{\# \# \#} P<0.001$ denote differences between treated diabetic group versus non-treated diabetic group.

control $(n=8)$ and three from diabetic $(n=8)$ rats were explanted on day 21 of gestation and cultured for $3 \mathrm{~h}$ in the presence or absence of the PPAR $\alpha$ agonists $\mathrm{LTB}_{4}$ $(0 \cdot 1 \mu \mathrm{M})$ or clofibrate $(20 \mu \mathrm{M})$, and placental lipid peroxidation and NO production were then analyzed. We found that neither clofibrate nor $\mathrm{LTB}_{4}$ modified TBARS concentrations in placentas from control rats. Differently, both LTB $_{4}(P<0.05)$ and clofibrate $(P<0 \cdot 01)$ were able to reduce the concentrations of TBARS in term placentas from diabetic animals (Fig. 4A). Moreover, the NO stable metabolites nitrates/nitrites were negatively regulated by both clofibrate and $\mathrm{LTB}_{4}$ in the placentas from both control $(P<0 \cdot 05)$ and diabetic $(P<0 \cdot 01)$ rats, with the PPAR $\alpha$ agonists in the diabetic group being capable of reducing NO production to control values (Fig. 4B).

\section{Lipid concentrations in placentas from control and diabetic rats at term gestation: effect of fetal $\mathrm{LTB}_{4}$ administration}

Considering that we previously found profound effects of in vivo fetal PPAR $\alpha$ activation on fetal liver lipid concentrations and fetal growth (Martinez et al. 2011), we tested the hypothesis that fetal PPAR $\alpha$ activation could influence placental lipid concentrations, NO production, and placental growth. For this purpose, fetuses from control and diabetic rats were injected with either $\operatorname{LTB}_{4}(0 \cdot 1 \mu \mathrm{M})$ or vehicle through the uterine wall on days 19, 20, and 21 of gestation. On day 21 of gestation, fetal blood was obtained to measure fetal glycemia, triglyceridemia, and cholesterolemia, and the placental weight and placental lipid concentrations were analyzed. Fetal glycemia $(P<0 \cdot 001)$, triglyceridemia $(P<0.05)$, and cholesterolemia $(P<0.05)$ were increased in the vehicle-injected fetuses from diabetic animals, when compared with the vehicle-injected control group (Fig. 5). Fetal administration of the natural PPAR $\alpha$ agonist $\mathrm{LTB}_{4}$ in late gestation did not change fetal glycemia, triglyceridemia, and cholesterolemia in both control and diabetic animals when compared with their respective vehicle-injected groups (Fig. 5). In control animals, the fetal administration of
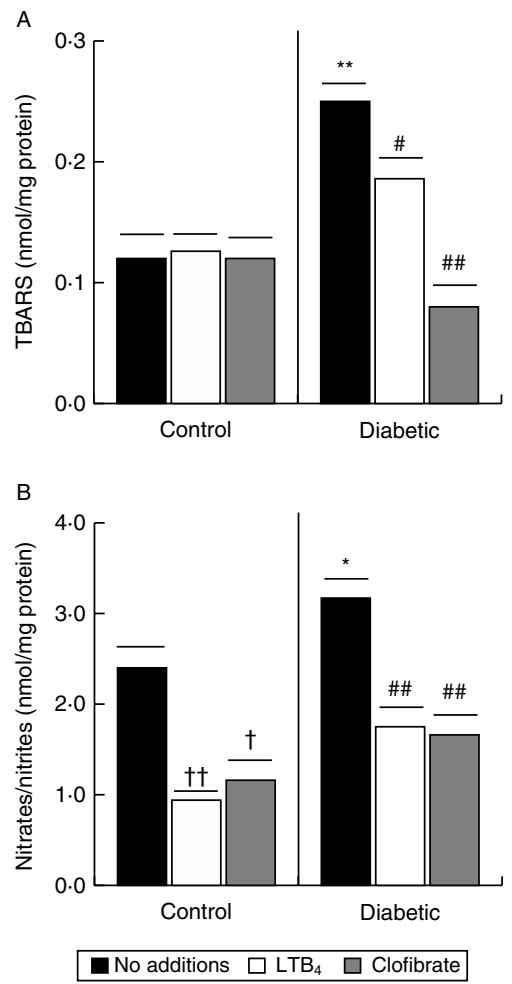

Figure 4 PPAR $\alpha$ activators regulate lipid peroxidation and NO production in term placentas from diabetic rats. Effect of the PPAR $\alpha$ agonists $\mathrm{LTB}_{4}(0.1 \mu \mathrm{M})$ and clofibrate $(20 \mu \mathrm{M})$ on $(\mathrm{A})$ lipid peroxidation and (B) NO production in term placentas from control and diabetic rats. Values are mean \pm S.E.M. for placentas obtained from eight rats on day 21 of gestation. ANOVA followed by Tukey's test was performed. ${ }^{\star} P<0.05$ and ${ }^{* \star} P<0.01$ denote differences between non-treated diabetic group versus nontreated control group. ${ }^{\dagger} P<0.05$ and ${ }^{\dagger \dagger} P<0.01$ denote differences between treated control group versus non-treated control group. ${ }^{\#} P<0.05$ and ${ }^{\# \#} P<0.01$ denote differences between treated diabetic group versus non-treated diabetic group. 

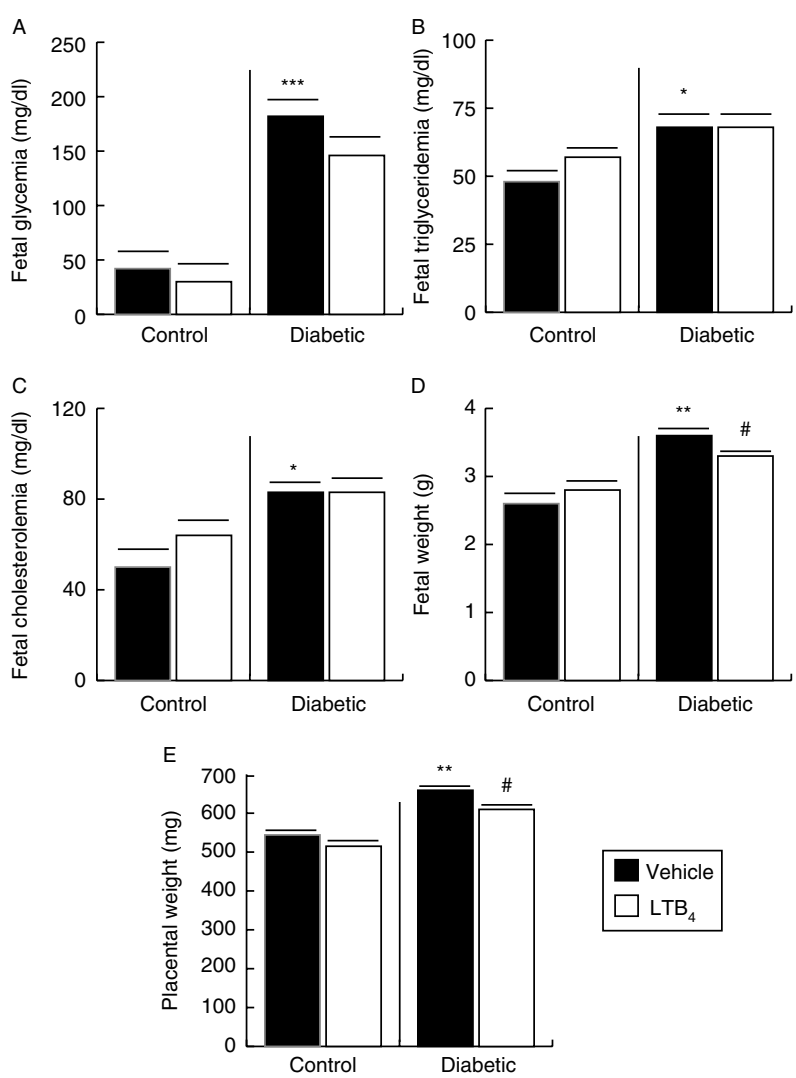

Figure 5 Fetal PPAR $\alpha$ activation reduces fetal and placental weight and does not modify serum lipid profile in diabetic rats on day 21 of gestation. Fetuses from control and diabetic rats were injected with $\mathrm{LTB}_{4}(0.1 \mu \mathrm{M})$ or vehicle on days 19,20 , and 21 of pregnancy. Fetal glycemia $(A)$, triglyceridemia $(B)$, and cholesterolemia $(C)$, as well as fetal weight $(D)$ and placental weight $(E)$, were evaluated on day 21 of pregnancy. Values are mean \pm S.E.M.; $n=8$ rats per group. ANOVA followed by Tukey's test was performed. ${ }^{\star} P<0.05,{ }^{* *} P<0.01$, and ${ }^{* \star \star} P<0.001$ denote differences between vehicle-treated diabetic versus vehicletreated control groups. ${ }^{\#} P<0.05$ denotes differences between $\mathrm{LTB}_{4}$-treated diabetic group versus vehicle-treated diabetic group.

$\mathrm{LTB}_{4}$ in late gestation did not change fetal or placental weight. Differently, in diabetic animals, a reduction in both fetal growth and placental growth was found when $\mathrm{LTB}_{4}$ was injected in the fetuses compared with those injected with vehicle $(P<0 \cdot 05$, Fig. 5). On the other hand, no changes in the concentrations of the lipid species analyzed were found in the placentas corresponding to $\mathrm{LTB}_{4}$-injected fetuses from control and diabetic rats when compared with their respective vehicle-injected controls (Fig. 6).

\section{Lipid peroxidation and NO production in placentas from control and diabetic rats at term gestation: effect of fetal $\mathrm{LTB}_{4}$ administration}

In order to analyze whether fetal PPAR $\alpha$ activation regulates lipid peroxidation and NO production in rat term placentas, fetuses from control and diabetic rats were injected with either $\operatorname{LTB}_{4}(0 \cdot 1 \mu \mathrm{M})$ or vehicle (controls) through the uterine wall on days 19, 20, and 21 of gestation. On day 21 of gestation, the placentas were explanted and TBARS and nitrates/nitrites concentrations were analyzed as respective indexes of lipid peroxidation and NO production. In addition, expression of the inducible isoform of iNOS was analyzed in the placentas corresponding to $\mathrm{LTB}_{4}$ - and vehicle-injected fetuses.

When we studied lipid peroxidation, there were no changes in this parameter in the placentas corresponding to $\mathrm{LTB}_{4}$-injected fetuses when compared with those corresponding to vehicle-injected fetuses in both control and diabetic rats (Fig. 7A). When we analyzed NO production, we found that in both control and diabetic groups, nitrates/nitrites concentrations were reduced in the placentas corresponding to $\mathrm{LTB}_{4^{-}}$ injected fetuses when compared with their respective vehicle-injected groups $(P<0 \cdot 05$, Fig. 7B). Interestingly, in the vehicle-injected diabetic group, which showed an increase in NO stable metabolites nitrates/ nitrites in the placenta when compared with the vehicle-injected control group, there was also an increase in the placental expression of iNOS $(P<0 \cdot 05$, Fig. 7C). Moreover, in the diabetic group,
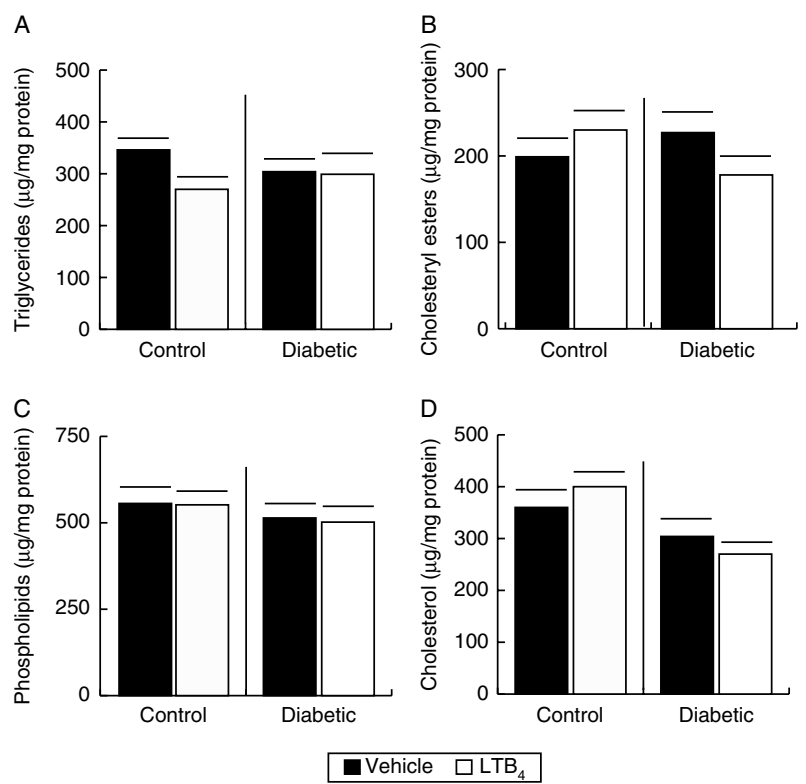

Figure 6 Fetal PPAR $\alpha$ activation does not modify lipid concentrations in the placenta. Fetuses from control and diabetic rats were injected with $\mathrm{LTB}_{4}(0 \cdot 1 \mu \mathrm{M})$ or vehicle on days 19,20 , and 21 of pregnancy and their corresponding placentas analyzed on day 21 of pregnancy. Concentrations of

(A) triglycerides, (B) cholesteryl esters, (C) phospholipids, and (D) cholesterol were evaluated in term placentas obtained from control and diabetic rats. Values are mean \pm s.E.M. for placentas obtained from eight rats on day 21 of pregnancy. ANOVA followed by Tukey's test was performed. 


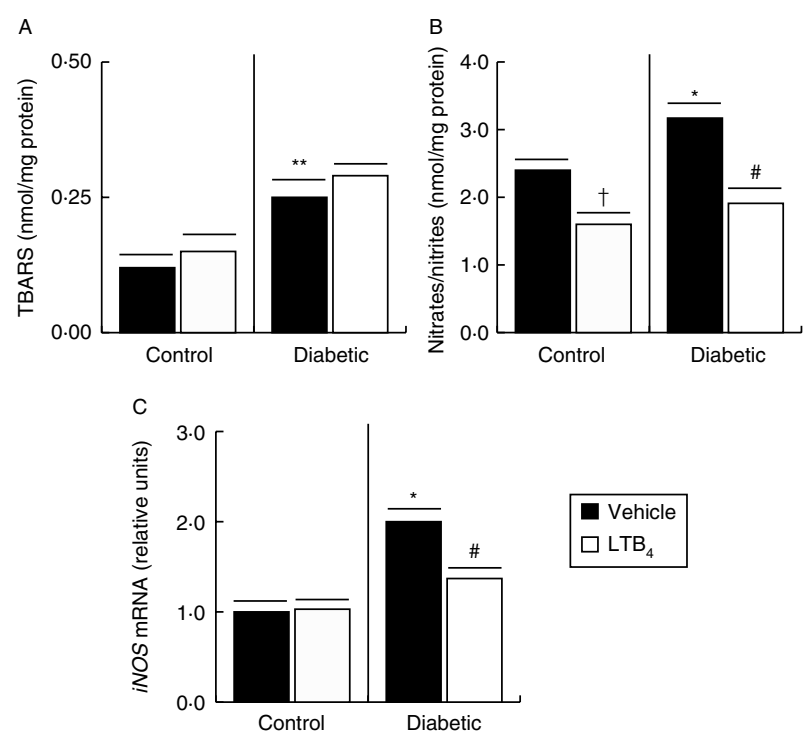

Figure 7 Fetal PPAR $\alpha$ activation does not modify lipid peroxidation but negatively regulates NO production and iNOS expression in the placenta from diabetic rats. Fetuses from control and diabetic rats were injected with $\operatorname{LTB}_{4}(0.1 \mu \mathrm{M})$ or vehicle on days 19,20 , and 21 of pregnancy and their corresponding placentas analyzed on day 21 of pregnancy. Concentrations of (A) TBARS, an index of lipid peroxidation, (B) nitrates/nitrites, stable NO metabolites, and (C) iNOS expression were evaluated in term placentas obtained from control and diabetic rats. Values are mean \pm S.E.M. for placentas obtained from eight rats on day 21 of gestation. ANOVA followed by Tukey's test was performed. ${ }^{\star} P<0.05$ and ${ }^{* *} P<0.01$ denote differences between vehicletreated diabetic group versus vehicle-treated control group. ${ }^{\dagger} P<0.05$ denotes differences between $\mathrm{LTB}_{4}$-treated control group versus vehicle-treated control group. ${ }^{\#} P<0.05$ denotes differences between $\mathrm{LTB}_{4}$-treated diabetic group versus vehicletreated diabetic group.

together with the reduction of nitrate/nitrite concentrations to control values, the expression of iNOS was also reduced in the placentas corresponding to LTB $_{4}$-injected fetuses when compared with the placentas corresponding to the vehicle-injected fetuses $(P<0 \cdot 05$, Fig. 7C $)$.

\section{PPAR $\alpha$ expression in placentas from control and diabetic rats at term gestation: effect of fetal $\mathrm{LTB}_{4}$ administration}

In order to analyze whether fetal administration of the endogenous PPAR $\alpha$ agonist $\mathrm{LTB}_{4}$ regulates the expression of PPAR $\alpha$ in rat term placentas, fetuses from control and diabetic rats were injected with either $\mathrm{LTB}_{4}$ $(0 \cdot 1 \mu \mathrm{M})$ or vehicle (controls) through the uterine wall on days 19, 20, and 21 of gestation. On day 21 of gestation, the placentas were explanted and PPAR $\alpha$ expression was analyzed.

A reduction in PPAR $\alpha$ expression was found in placentas from diabetic animals injected with vehicle when compared with those from control animals injected with vehicle $(P<0 \cdot 05$, Fig. 8). Interestingly, when we studied the effect of fetal $\mathrm{LTB}_{4}$ administration, there were significant increases in placental PPAR $\alpha$ expression in the $\mathrm{LTB}_{4}$-injected fetuses from both control and diabetic rats when compared with those corresponding to vehicle-injected fetuses in both control and diabetic groups $(P<0 \cdot 01$, Fig. 8$)$.

\section{Discussion}

PPARs signaling pathways are important in placental development and function, and their altered concentrations have relevance in several gestational diseases (Giaginis et al. 2008, Wieser et al. 2008, Arck et al. 2010). In this study, we found reduced PPAR $\alpha$ concentrations in term placentas from diabetic rats. Similarly, protein expression of PPAR $\alpha$ is reduced in term placentas from gestational diabetic patients (Holdsworth-Carson et al. 2010). These changes seem to be dependent on the developmental stage, as PPAR $\alpha$ concentrations are enhanced in placentas from diabetic rats in the early post-placentation period (Martinez et al. 2008). In this regard, changes in concentrations and function of the different PPAR isoforms occur throughout pregnancies both in humans and in experimental models (Capobianco et al. 2005, Wieser et al. 2008, Holdsworth-Carson et al. 2009, Lappas \& Rice 2009, Pustovrh et al. 2009). In this research, in the in vitro experiments performed in placentas at term gestation, we found some effects

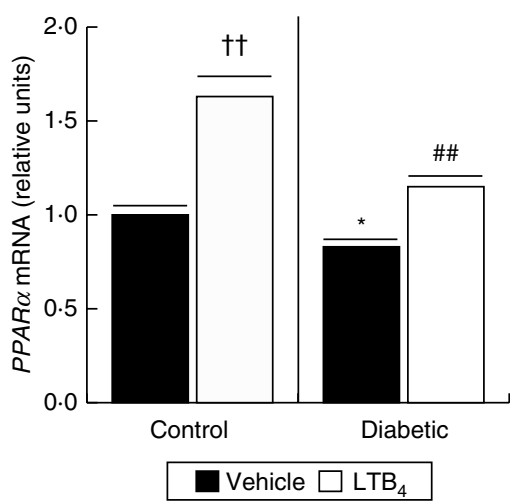

Figure 8 Fetal $\mathrm{LTB}_{4}$ upregulates PPAR $\alpha$ expression in placentas from diabetic rats. Fetuses from control and diabetic rats were injected with $\mathrm{LTB}_{4}(0 \cdot 1 \mu \mathrm{M})$ or vehicle on days 19,20 , and 21 of pregnancy and their corresponding placentas analyzed on day 21 of pregnancy. PPAR $\alpha$ expression was evaluated in term placentas obtained from control and diabetic rats. Values are mean \pm S.E.M. for placentas obtained from eight rats on day 21 of gestation. ANOVA followed by Tukey's test was performed. ${ }^{\star} P<0.05$ denotes differences between vehicle-treated diabetic group versus vehicle-treated control group. ${ }^{\dagger \dagger} P<0.01$ denotes differences between $\mathrm{LTB}_{4}$-treated control group versus vehicletreated control group. ${ }^{\# \#} P<0.01$ denotes differences between $\mathrm{LTB}_{4}$-treated diabetic group versus vehicle-treated diabetic group. 
related to the capacity of lipid oxidation of clofibrate, a potent $\operatorname{PPAR} \alpha$ pharmacological activator, but no changes in the presence of the endogenous ligand $\mathrm{LTB}_{4}$, capable of oxidizing lipids in placentas at midgestation (Martinez et al. 2008). The capacity of lipid accretion of the placenta changes throughout gestation. Indeed, at midgestation, placentas from diabetic rats show a marked accumulation of triglycerides and cholesteryl esters (Martinez et al. 2008) whereas term placentas from the same diabetic rat model showed no lipid overaccumulation. These findings suggest that changes in lipid metabolism occur at term gestation in parallel to important changes in the concentrations of PPAR $\alpha$. On the other hand, although both clofibrate and $\mathrm{LTB}_{4}$ can activate lipid metabolism through PPAR $\alpha$ signaling pathways in several tissues including the placenta (Lefebvre $e t$ al. 2006, Finck 2007, Martinez et al. 2008), different effects can be achieved due to the high potency of clofibrate and the different conformational changes that each ligand can induce, leading to the recruitment of different co-activators and to the release of different co-repressors (Schaiff et al. 2000, Martinez et al. 2008, Panadero et al. 2009, Yoon 2009). Therefore, a limitation of the present work that needs to be addressed in further studies is the evaluation of the activation of PPAR $\alpha$ achieved by each ligand.

Regarding the placental de novo lipid synthesis, we here found that PPAR $\alpha$ activation regulates the synthesis of triglycerides, phospholipids, and cholesterol in diabetic tissues. Indeed, although mainly a regulator of lipid catabolism, PPAR $\alpha$ can also regulate lipid synthesis in different tissues (Rakhshandehroo et al. 2007, Panadero et al. 2009), an effect that may be related to PPARs interaction with the liver receptor $\mathrm{X}$ (LXR), a main regulator of this anabolic pathway (van Straten et al. 2009, Hein et al. 2010).

Both the classical PPARs activation pathway and the transactivation of other nuclear transcription factors such as NF- $\kappa \mathrm{B}$ have been related to PPARs antiinflammatory effects (Straus \& Glass 2007, Bensinger \& Tontonoz 2008). Indeed, PPARs activation both stimulates the expression of the antioxidant enzyme superoxide dismutase and catalase, and regulates glutathione metabolism in several cell types (Lin et al. 2007, Abdelmegeed et al. 2009, Ibarra-Lara et al. 2010). Activation of PPAR $\alpha$ also regulates lipid peroxidation, a regulation evident in plasma and tissues in different pathologies and inflammatory conditions including the diabetic state (Inoue et al. 1997, Anwer et al. 2007, Belfort et al. 2010). NO production is negatively regulated by PPAR $\alpha$ activation in different tissues, through a mechanism in part related to the reduction of iNOS concentrations (Paukkeri et al. 2007, Cuzzocrea et al. 2008, Ibarra-Lara et al. 2010). In this study, we found that $\operatorname{PPAR} \alpha$ activation negatively regulates lipid peroxidation and NO production in the placenta, an effect that is particularly relevant in maternal diabetes, in which the excess of reactive oxygen and nitrogen species are clearly related to the damaging effects in placental tissues (Jawerbaum \& Gonzalez 2006, Webster et al. 2008).

An important question addressed in this work is whether the fetus can actively regulate placental function and growth in an adverse environment such as maternal diabetes. Our experimental approach allowed the evaluation of a fetal role in regulating placental lipid metabolism, NO production, and growth. We here found that fetal administration of the endogenous PPAR $\alpha$ ligand $\mathrm{LTB}_{4}$ does not change lipid concentrations and peroxidation in the placenta, but specifically regulates the production of placental NO, through a mechanism that seems to depend, at least in part in the diabetic animals, on a downregulation of the expression of the inducible isoform of NOS. Although further research is needed to understand the direct or indirect nature of the effect of fetal $\mathrm{LTB}_{4}$ on the placenta, the observed responses to fetal $\mathrm{LTB}_{4}$ in this tissue may be due to its effect on the placental endothelial cells, which have a high capacity of NO synthesis and are likely to be the placental cells most exposed to fetal signaling molecules (Giannubilo et al. 2008).

A limitation of this study was that it was not possible to address the in vivo effects of the pharmacological ligand clofibrate, as vehicles needed to dissolve this drug impaired development in rat fetuses at term. Nevertheless, our recent studies performed in term pregnant rats have shown potent effects of the PPAR $\alpha$ agonist $\mathrm{LTB}_{4}$ on fetal liver lipid catabolism when the drug was given to the fetuses for three consecutive days, even more potent than those achieved in vitro by both $\mathrm{LTB}_{4}$ and clofibrate in fetal liver tissues (Martinez et al. 2011).

In this work, we found that PPAR $\alpha$ expression was reduced in the placentas from diabetic rats when compared with controls. Moreover, fetal administration of the PPAR $\alpha$ ligand $\mathrm{LTB}_{4}$ highly increased PPAR $\alpha$ expression in the placentas from both control and diabetic rats. This finding provides direct evidence of an $\mathrm{LTB}_{4}$-mediated increase in the PPAR $\alpha$ signaling pathway. As previous studies have shown that PPAR $\alpha$ dietary ligands in the mother can increase PPAR $\alpha$ mediated pathways in the fetuses (Ringseis et al. 2007), this suggests that PPAR $\alpha$ agonists are relevant as both mother-to-fetus and fetus-to-mother signaling molecules.

Together with the changes in placental NO production, iNOS expression, and PPAR $\alpha$ expression, a reduction in placental growth was observed in the placentas corresponding to the $\mathrm{LTB}_{4}$-injected fetuses in diabetic animals. This is important because of the 
placental overgrowth characteristic in maternal diabetes and the relationship between placental growth and function and the abnormal intrauterine programming in the fetuses (Catalano \& Kirwan 2001, Gatford et al. 2010, Thornburg et al. 2010). Besides, our results suggest that the fetus has an active role in the regulation of growth in their placentas, an effect evident in a context in which the fetus is exposed to an adverse environment due to maternal diabetes. Although it is difficult to pinpoint the mechanism involved in the observed reduction of placental growth, our results suggest that it may be related to normalization of the production of $\mathrm{NO}$, a pro-angiogenic and vasodilator agent (Dulak \& Jozkowicz 2003, Valdes et al. 2009), and not to changes in lipid concentrations and peroxidation, parameters that do not change when PPAR $\alpha$ is activated in the fetuses. On the other hand, studies performed in trophoblasts and different cell types have shown that PPARs activation affects cell proliferation, differentiation, and apoptosis (Lin et al. 2007, Barak et al. 2008, Fournier et al. 2008, Parast et al. 2009, Arck et al. 2010, Benameur et al. 2010), suggesting that there may be many pathways related to placental growth that could be regulated by activating fetal $\operatorname{PPAR} \alpha$ that deserves further study.

In conclusion, our findings on PPAR $\alpha$ signaling in term placentas from diabetic rats provide evidence of its role as a regulator of lipid metabolism, lipid peroxidation, and NO production in term placentas, signaling pathways specially relevant in maternal diabetes. Besides, we here demonstrate that fetal administration of $\mathrm{LTB}_{4}$ can modulate placental $\mathrm{NO}$ production, iNOS expression, and PPAR $\alpha$ expression, as well as placental weight, suggesting a specific role of this endogenous PPAR $\alpha$ activator in the fetus in the regulation of placental functions and growth.

\section{Declaration of interest}

The authors declare that there is no conflict of interest that could be perceived as prejudicing the impartiality of the research reported.

\section{Funding}

This work was supported by grants from Agencia de Promoción Científica y Tecnológica of Argentina (PICT 2005-32268 and PICT 2006-00084).

\section{Acknowledgements}

We would like to acknowledge the valuable contribution of Dr Gernot Desoye in the design of the in vivo experimental approach.

\section{References}

Abdelmegeed MA, Moon KH, Hardwick JP, Gonzalez FJ \& Song BJ 2009 Role of peroxisome proliferator-activated receptor-alpha in fasting-mediated oxidative stress. Free Radical Biology and Medicine $\mathbf{4 7}$ 767-778. (doi:10.1016/j.freeradbiomed.2009.06.017)

Anwer T, Sharma M, Pillai KK, Haque SE, Alam MM \& Zaman MS 2007 Protective effect of bezafibrate on streptozotocin-induced oxidative stress and toxicity in rats. Toxicology 229 165-172. (doi:10.1016/j.tox. 2006.10.016)

Arck P, Toth B, Pestka A \& Jeschke U 2010 Nuclear receptors of the peroxisome proliferator-activated receptor (PPAR) family in gestational diabetes: from animal models to clinical trials. Biology of Reproduction 83 168-176. (doi:10.1095/biolreprod.110.083550)

Balsells M, Garcia-Patterson A, Gich I \& Corcoy R 2009 Maternal and fetal outcome in women with type 2 versus type 1 diabetes mellitus: a systematic review and metaanalysis. Journal of Clinical Endocrinology and Metabolism 94 4284-4291. (doi:10.1210/jc.2009-1231)

Barak Y, Sadovsky Y \& Shalom-Barak T 2008 PPAR signaling in placental development and function. PPAR Research 2008142082. (doi:10.1155/2008/142082)

Belfort R, Berria R, Cornell J \& Cusi K 2010 Fenofibrate reduces systemic inflammation markers independent of its effects on lipid and glucose metabolism in patients with the metabolic syndrome. Journal of Clinical Endocrinology and Metabolism 95 829-836. (doi:10. 1210/jc.2009-1487)

Benameur T, Tual-Chalot S, Andriantsitohaina R \& Martinez MC 2010 PPARalpha is essential for microparticle-induced differentiation of mouse bone marrow-derived endothelial progenitor cells and angiogenesis. PLoS ONE 5 e12392. (doi:10.1371/journal.pone. 0012392)

Bensinger SJ \& Tontonoz P 2008 Integration of metabolism and inflammation by lipid-activated nuclear receptors. Nature $\mathbf{4 5 4}$ 470-477. (doi:10.1038/nature07202)

Braissant O \& Wahli W 1998 Differential expression of peroxisome proliferator-activated receptor-alpha, -beta, and -gamma during rat embryonic development. Endocrinology 139 2748-2754. (doi:10. $1210 /$ en.139.6.2748)

Capobianco E, Jawerbaum A, Romanini MC, White V, Pustovrh C, Higa R, Martinez N, Mugnaini MT, Sonez C \& Gonzalez E 2005 15-Deoxy-delta(12,14)-prostaglandin J2 and peroxisome proliferator-activated receptor gamma (PPARgamma) levels in term placental tissues from control and diabetic rats: modulatory effects of a PPARgamma agonist on nitridergic and lipid placental metabolism. Reproduction, Fertility, and Development 17 423-433. (doi:10.1071/RD04067)

Capobianco E, White V, Higa R, Martinez N \& Jawerbaum A 2008 Effects of natural ligands of PPARgamma on lipid metabolism in placental tissues from healthy and diabetic rats. Molecular Human Reproduction 14 491-499. (doi:10.1093/molehr/gan039)

Catalano PM \& Kirwan JP 2001 Maternal factors that determine neonatal size and body fat. Current Diabetes Reports 1 71-77. (doi:10. 1007/s11892-001-0013-y)

Cuzzocrea S, Bruscoli S, Mazzon E, Crisafulli C, Donato V, Di Paola R, Velardi E, Esposito E, Nocentini G \& Riccardi C 2008 Peroxisome proliferator-activated receptor-alpha contributes to the antiinflammatory activity of glucocorticoids. Molecular Pharmacology 73 323-337. (doi:10.1124/mol.107.041475)

Desoye G \& Shafrir E 1994 Placental metabolism and its regulation in health and diabetes. Molecular Aspects of Medicine 15 505-682. (doi:10.1016/0098-2997(94)90004-3)

Desvergne B, Michalik L \& Wahli W 2004 Be fit or be sick: peroxisome proliferator-activated receptors are down the road. Molecular Endocrinology 18 1321-1332. (doi:10.1210/me.2004-0088)

Dulak J \& Jozkowicz A 2003 Regulation of vascular endothelial growth factor synthesis by nitric oxide: facts and controversies. Antioxidants and Redox Signaling 5 123-132. (doi:10.1089/152308603321223612) 
Finck BN 2007 The PPAR regulatory system in cardiac physiology and disease. Cardiovascular Research 73 269-277. (doi:10.1016/j.cardiores.2006.08.023)

Fournier T, Handschuh K, Tsatsaris V, Guibourdenche J \& Evain-Brion D 2008 Role of nuclear receptors and their ligands in human trophoblast invasion. Journal of Reproductive Immunology 77 161-170. (doi:10.1016/j.jri.2007.05.004)

Gatford KL, Simmons RA, De Blasio MJ, Robinson JS \& Owens JA 2010 Review: placental programming of postnatal diabetes and impaired insulin action after IUGR. Placenta 31 (Supplement) S60-S65. (doi:10.1016/j.placenta.2009.12.015)

Giaginis C, Spanopoulou E \& Theocharis S 2008 PPAR-gamma signaling pathway in placental development and function: a potential therapeutic target in the treatment of gestational diseases. Expert Opinion on Therapeutic Targets 12 1049-1063. (doi:10.1517/ 14728222.12.8.1049)

Giannubilo SR, Menegazzi M, Tedeschi E, Bezzeccheri V, Suzuki H \& Tranquilli AL 2008 Doppler analysis and placental nitric oxide synthase expression during fetal growth restriction. Journal of Maternal-Fetal E̋ Neonatal Medicine 21 617-622. (doi:10.1080/ $14767050802214774)$

Green LC, Wagner DA, Glogowski J, Skipper PL, Wishnok JS \& Tannenbaum SR 1982 Analysis of nitrate, nitrite, and [15N]nitrate in biological fluids. Analytical Biochemistry 126 131-138. (doi:10. 1016/0003-2697(82)90118-X)

Hein GJ, Bernasconi AM, Montanaro MA, Pellon-Maison M, Finarelli G, Chicco A, Lombardo YB \& Brenner RR 2010 Nuclear receptors and hepatic lipidogenic enzyme response to a dyslipidemic sucrose-rich diet and its reversal by fish oil $n-3$ polyunsaturated fatty acids. American Journal of Physiology, Endocrinology and Metabolism 298 E429-E439. (doi:10.1152/ajpendo.00513.2009)

Herrera E \& Ortega-Senovilla H 2010 Disturbances in lipid metabolism in diabetic pregnancy - are these the cause of the problem? Best Practice E Research. Clinical Endocrinology and Metabolism 24 515-525. (doi:10.1016/j.beem.2010.05.006)

Hiden U, Glitzner E, Hartmann M \& Desoye G 2009 Insulin and the IGF system in the human placenta of normal and diabetic pregnancies. Journal of Anatomy 215 60-68. (doi:10.1111/j.14697580.2008.01035.x)

Higa R, White V, Martinez N, Kurtz M, Capobianco E \& Jawerbaum A 2010 Safflower and olive oil dietary treatments rescue aberrant embryonic arachidonic acid and nitric oxide metabolism and prevent diabetic embryopathy in rats. Molecular Human Reproduction 16 286-295. (doi:10.1093/molehr/gap109)

Hihi AK, Michalik L \& Wahli W 2002 PPARs: transcriptional effectors of fatty acids and their derivatives. Cellular and Molecular Life Sciences 59 790-798. (doi:10.1007/s00018-002-8467-x)

Holdsworth-Carson SJ, Permezel M, Riley C, Rice GE \& Lappas M 2009 Peroxisome proliferator-activated receptors and retinoid $\mathrm{X}$ receptor-alpha in term human gestational tissues: tissue specific and labour-associated changes. Placenta 30 176-186. (doi:10.1016/j. placenta.2008.11.013)

Holdsworth-Carson SJ, Lim R, Mitton A, Whitehead C, Rice GE, Permezel M \& Lappas M 2010 Peroxisome proliferator-activated receptors are altered in pathologies of the human placenta: gestational diabetes mellitus, intrauterine growth restriction and preeclampsia. Placenta 31 222-229. (doi:10.1016/j.placenta.2009. 12.009)

Ibarra-Lara L, Cervantes-Perez LG, Perez-Severiano F, Del Valle L, Rubio-Ruiz E, Soria-Castro E, Pastelin-Hernandez GS, SanchezAguilar M, Martinez-Lazcano JC \& Sanchez-Mendoza A 2010 PPARalpha stimulation exerts a blood pressure lowering effect through different mechanisms in a time-dependent manner. European Journal of Pharmacology 627 185-193. (doi:10.1016/j.ejphar. 2009.10.039)

Inoue I, Noji S, Shen MZ, Takahashi K \& Katayama S 1997 The peroxisome proliferator-activated receptor alpha (PPAR alpha) regulates the plasma thiobarbituric acid-reactive substance (TBARS) level. Biochemical and Biophysical Research Communications 237 606-610. (doi:10.1006/bbrc.1997.7196)

Jansson T, Cetin I, Powell TL, Desoye G, Radaelli T, Ericsson A \& Sibley CP 2006 Placental transport and metabolism in fetal overgrowth - a workshop report. Placenta 27 (Supplement A) S109-S113. (doi:10.1016/j.placenta.2006.01.017)

Jawerbaum A \& Gonzalez E 2005 The role of alterations in arachidonic acid metabolism and nitric oxide homeostasis in rat models of diabetes during early pregnancy. Current Pharmaceutical Design 11 1327-1342. (doi:10.2174/1381612053507503)

Jawerbaum A \& Gonzalez E 2006 Diabetic pregnancies: the challenge of developing in a pro-inflammatory environment. Current Medicinal Chemistry 13 2127-2138. (doi:10.2174/09298670 6777935302)

Jawerbaum A \& White V 2010 Animal models in diabetes and pregnancy. Endocrine Reviews 31 680-701. (doi:10.1210/er.20090038)

Kurtz M, Capobianco E, Martinez N, Fernandez J, Higa R, White V \& Jawerbaum A 2010 Carbaprostacyclin, a PPARdelta agonist, ameliorates excess lipid accumulation in diabetic rat placentas. Life Sciences 86 781-790. (doi:10.1016/j.lfs.2010.03.008)

Lappas M \& Rice GE 2009 Transcriptional regulation of the processes of human labour and delivery. Placenta 30 (Supplement A) S90-S95. (doi:10.1016/j.placenta.2008.10.005)

Leach L, Taylor A \& Sciota F 2009 Vascular dysfunction in the diabetic placenta: causes and consequences. Journal of Anatomy 215 69-76. (doi:10.1111/j.1469-7580.2009.01098.x)

Lefebvre P, Chinetti G, Fruchart JC \& Staels B 2006 Sorting out the roles of PPAR alpha in energy metabolism and vascular homeostasis. Journal of Clinical Investigation 116 571-580. (doi:10.1172/ JCI27989)

Lin Q, Ruuska SE, Shaw NS, Dong D \& Noy N 1999 Ligand selectivity of the peroxisome proliferator-activated receptor alpha. Biochemistry 38 185-190. (doi:10.1021/bi9816094)

Lin H, Hou CC, Cheng CF, Chiu TH, Hsu YH, Sue YM, Chen TH, Hou HH, Chao YC, Cheng TH et al. 2007 Peroxisomal proliferatoractivated receptor-alpha protects renal tubular cells from doxorubicin-induced apoptosis. Molecular Pharmacology 72 1238-1245. (doi:10.1124/mol.107.037523)

Martinez N, Capobianco E, White V, Pustovrh MC, Higa R \& Jawerbaum A 2008 Peroxisome proliferator-activated receptor alpha activation regulates lipid metabolism in the feto-placental unit from diabetic rats. Reproduction 136 95-103. (doi:10.1530/REP08-0028)

Martinez N, White V, Kurtz M, Higa R, Capobianco E \& Jawerbaum A 2011 Activation of the nuclear receptor PPARalpha regulates lipid metabolism in foetal liver from diabetic rats: implications in diabetes-induced foetal overgrowth. Diabetes Metabolism Research and Reviews 27 35-46. (doi:10.1002/dmrr.1151)

Melamed N \& Hod M 2009 Perinatal mortality in pregestational diabetes. International Journal of Gynaecology and Obstetrics 104 (Supplement 1) S20-S24. (doi:10.1016/j.ijgo.2008.11.024)

Michael Weindling A 2009 Offspring of diabetic pregnancy: short-term outcomes. Seminars in Fetal and Neonatal Medicine 14 111-118. (doi:10.1016/j.siny.2008.11.007)

Myatt L \& Cui X 2004 Oxidative stress in the placenta. Histochemistry and Cell Biology 122 369-382. (doi:10.1007/s00418-004-0677-x)

Narala VR, Adapala RK, Suresh MV, Brock TG, Peters-Golden M \& Reddy RC 2010 Leukotriene $\mathrm{B}_{4}$ is a physiologically relevant endogenous peroxisome proliferator-activated receptor-alpha agonist. Journal of Biological Chemistry 285 22067-22074. (doi:10. 1074/jbc.M109.085118)

Nowicki MJ, Shi D, Cai Z, Bishop PR \& May WL 2003 Developmental expression of endothelial nitric oxide synthase (eNOS) in the rat liver. Pediatric Research 54 732-738. (doi:10.1203/01.PDR. 0000086904.52847.2A) 
Ohkawa H, Ohishi N \& Yagi K 1979 Assay for lipid peroxides in animal tissues by thiobarbituric acid reaction. Analytical Biochemistry 95 351-358. (doi:10.1016/0003-2697(79)90738-3)

Panadero MI, Gonzalez MC, Herrera E \& Bocos C 2009 Factors modulating fibrates response: therapeutic implications and alternative strategies. Endocrine, Metabolic and Immune Disorders Drug Targets 9 219-236. (doi:10.2174/187153009789044356)

Parast MM, Yu H, Ciric A, Salata MW, Davis V \& Milstone DS 2009 PPARgamma regulates trophoblast proliferation and promotes labyrinthine trilineage differentiation. PLOS ONE 4 e8055. (doi:10. 1371/journal.pone.0008055)

Paukkeri EL, Leppanen T, Sareila O, Vuolteenaho K, Kankaanranta H \& Moilanen E 2007 PPARalpha agonists inhibit nitric oxide production by enhancing iNOS degradation in LPS-treated macrophages. British Journal of Pharmacology 152 1081-1091. (doi:10. 1038/sj.bjp.0707477)

Plagemann A, Harder T \& Dudenhausen JW 2008 The diabetic pregnancy, macrosomia, and perinatal nutritional programming. Nestlé Nutrition Workshop Series. Paediatric Programme 61 91-102. (doi:10.1159/000113179)

Portha B, Picon L \& Rosselin G 1979 Chemical diabetes in the adult rat as the spontaneous evolution of neonatal diabetes. Diabetologia $\mathbf{1 7}$ 371-377. (doi:10.1007/BF01236272)

Pustovrh MC, Capobianco E, Martinez N, Higa R, White V \& Jawerbaum A 2009 MMP/TIMP balance is modulated in vitro by $15 \mathrm{dPGJ}(2)$ in fetuses and placentas from diabetic rats. European Journal of Clinical Investigation 39 1082-1090. (doi:10.1111/j.13652362.2009.02200.x)

Rakhshandehroo M, Sanderson LM, Matilainen M, Stienstra R, Carlberg C, de Groot PJ, Muller M \& Kersten S 2007 Comprehensive analysis of PPARalpha-dependent regulation of hepatic lipid metabolism by expression profiling. PPAR Research 200726839. (doi:10.1155/2007/26839)

Reece EA, Leguizamon G \& Wiznitzer A 2009 Gestational diabetes: the need for a common ground. Lancet 373 1789-1797. (doi:10.1016/ S0140-6736(09) 60515-8)

Ringseis R, Gutgesell A, Dathe C, Brandsch C \& Eder K 2007 Feeding oxidized fat during pregnancy up-regulates expression of PPARalpha-responsive genes in the liver of rat fetuses. Lipids in Health and Disease 6 6. (doi:10.1186/1476-511X-6-6)

San Martin R \& Sobrevia L 2006 Gestational diabetes and the adenosine/L-arginine/nitric oxide (ALANO) pathway in human umbilical vein endothelium. Placenta 27 1-10. (doi:10.1016/j. placenta.2005.01.011)
Schaiff WT, Carlson MG, Smith SD, Levy R, Nelson DM \& Sadovsky Y 2000 Peroxisome proliferator-activated receptor-gamma modulates differentiation of human trophoblast in a ligand-specific manner. Journal of Clinical Endocrinology and Metabolism 85 3874-3881. (doi:10.1210/jc.85.10.3874)

van Straten E, van Meer H, Huijkman N, van Dijk TH, Baller JF, Verkade HJ, Kuipers F \& Plosch T 2009 Fetal liver X receptor activation acutely induces lipogenesis, but does not affect plasma lipid response to a high-fat diet in adult mice. American Journal of Physiology, Endocrinology and Metabolism 297 E1171-E1178. (doi:10. 1152/ajpendo.00021.2009)

Straus DS \& Glass CK 2007 Anti-inflammatory actions of PPAR ligands: new insights on cellular and molecular mechanisms. Trends in Immunology 28 551-558. (doi:10.1016/j.it.2007.09.003)

Thornburg KL, O'Tierney P \& Louey S 2010 The placenta is a programming agent in cardiovascular disease. Placenta 31 S54-S59. (doi:10.1016/j.placenta.2010.01.002)

Valdes G, Kaufmann P, Corthorn J, Erices R, Brosnihan KB \& Joyner-Grantham J 2009 Vasodilator factors in the systemic and local adaptations to pregnancy. Reproductive Biology and Endocrinology 7 79. (doi:10.1186/1477-7827-7-79)

Wang Q, Fujii H \& Knipp GT 2002 Expression of PPAR and RXR isoforms in the developing rat and human term placentas. Placenta 23 661-671. (doi:10.1053/plac.2002.0855)

Webster RP, Roberts VH \& Myatt L 2008 Protein nitration in placenta functional significance. Placenta 29 985-994. (doi:10.1016/j.placenta.2008.09.003)

Wieser F, Waite L, Depoix C \& Taylor RN 2008 PPAR action in human placental development and pregnancy and its complications. PPAR Research 2008 527048. (doi:10.1155/2008/527048)

Yeon JE, Choi KM, Baik SH, Kim KO, Lim HJ, Park KH, Kim JY, Park JJ, Kim JS, Bak YT et al. 2004 Reduced expression of peroxisome proliferator-activated receptor-alpha may have an important role in the development of non-alcoholic fatty liver disease. Journal of Gastroenterology and Hepatology 19 799-804. (doi:10.1111/j.14401746.2004.03349.x)

Yoon M 2009 The role of PPARalpha in lipid metabolism and obesity: focusing on the effects of estrogen on PPARalpha actions. PharmacologicalResearch 60 151-159. (doi:10.1016/j.phrs.2009.02.004)

Received in final form 11 March 2011

Accepted 18 April 2011

Made available online as an Accepted Preprint 18 April 2011 